\title{
The Academic Library as a Gateway to the Internet: An Analysis of the Extent and Nature of Search Engine Access from Academic Library Home Pages
}

\author{
Carol A. Wright
}

\begin{abstract}
Academic libraries have the opportunity through their Web pages to present to the university community recommended sites and appropriate techniques for searching the Internet. But in the design and organization of home pages, academic libraries often provide inadequate navigational paths to sites that provide search engine selection and evaluation criteria. The author conducted a study of the home pages of 114 academic libraries that belong to the Association of Research Libraries (ARL) to determine their paths to Internet search engines. This paper presents the study results and makes recommendations for improvement.
\end{abstract}

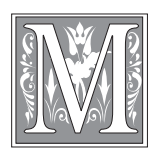

ost academic librarians regard the library as the primary gateway to information for the university community. They believe that they have a significant responsibility for information literacy instruction, specifically for the selection, use, and evaluation of multiple information resources, including Internet resources. But are libraries truly maximizing their ability to present the Internet to users in an organized manner? In the presentation of collections and services on library home pages, libraries often provide inadequate paths to resources, guides for selection, evaluation and use of search engines, and other navigational tools necessary for users to make intelligent and informed choices about resources beyond those owned and licensed in the institution's collections. A library's Web page is the most common vehicle for the delivery of instruction and information. "In the digital environment, a library web site is the virtual public face-the quasi-equivalent of the front door, signage, pathfinders, collections, services, and, to an extent, people." ${ }^{1}$ Yet, library Web pages often fail to serve as the campus information gateway to external resources. "The fact that the homepage is so often not the entry point underscores that what we think of as our homepage is not relevant to our users' needs." 2 Proficiency in the identification, selection, and use of Internet resources is a primary information literacy goal, clearly stated in the Information Literacy

Carol A. Wright is Education and Behavioral Sciences Librarian at Pennsylvania State University Libraries; e-mail: caw4@psu.edu. 
Competency Standards for Higher Education. $^{3}$ Academic librarians assert their role in support of the instructional and research mission of their institutions by developing comprehensive instruction programs that integrate the Internet with licensed library resources. For the library to support its claim as a gateway to information, in addition to providing access to its own purchased and licensed resources, it also should design its Web page to serve as a gateway for students to learn how to identify Internet search engines and strategies.

The purpose of this study is to determine the manner in which academic research libraries present links on their Web sites to search engines and guides to using the Internet. This study analyzed the library home pages of the 114 academic libraries of the Association of Research Libraries (ARL). Data were collected during August 2002 and reviewed in June 2003.

\section{Literature Review}

\section{The Current Information Environment for College Students: The Reality of the Internet}

The virtual library is described as having "created an information environment that is complex and fluid, connective and interactive, diverse and unpredictable, where the professional provision of information is no longer constrained by time and place." ${ }^{4}$ Recent studies have indicated that undergraduates regard the Internet as a primary information resource and that reliance on the Internet is increasing. The Pew Internet Project's "The Internet Goes to College" reports that nearly three-quarters (73\%) of college students said they use the Internet more than the library, whereas only nine percent said they use the library more than the Internet for information-searching. ${ }^{5}$ The OCLC White Paper on the Information
Habits of College Students reports that students say their first choices among Web resources are search engines and course-specific Web sites. ${ }^{6}$ Forty-two percent report using search engines for every assignment, whereas 37 percent use search engines for most assignments. These numbers are in striking contrast to those who report using a campus library Web site for every assignment (11\%) and for most assignments (30\%). This study also reported that more than 90 percent of students surveyed access the Web remotely from home computers, 75 percent of college students have confidence in their abilities to locate information for their assignments, and 70 percent feel that they are successful at finding what they need most of the time.

In "How and Why Are Libraries Changing," Denise Troll noted that undergraduate students appear to value convenience and delivery speed more than quality of information. ${ }^{7}$ She confirmed the Web use data reported in the OCLC White Paper by reporting that focus group and survey research indicates that undergraduate students typically first turn to popular Web search engines when they need to find information and that there is no evidence that students use more than one search engine when they look for information. But she painted an even more challenging picture by noting that these search engines index only the "surface Web," where less than seven percent of the information is appropriate for educational or scholarly purposes. The "deep Web" is even less accessible to students who do not understand the distinction. Even when students do understand the limitations of the information they find on the Web, Troll noted that "the growing concern that many undergraduate students may be searching only a fraction of the web to complete their assignments, ignoring entirely the 
books, journals, databases, full-text digital resources and other scholarly materials provided by the library. Because of easy access to the web, undergraduates are using library collections and services less than in the past and, in the absence of quality information and tools on the surface, this may imperil the quality of student learning." This student behavior was confirmed by Deborah J. Grimes and Carol H. Boening, who, through interviews with students, learned that many bypassed library resources, went directly to the Web, and described their Internet search as "very easy" despite the fact that their sources were of lesser quality than expected. ${ }^{8}$ In an environment where no single Web search engine indexes more than 16 percent of the surface Web, these user behaviors do not suggest satisfactory search results. ${ }^{9}$

\section{Faculty Experiences with Student Internet Use}

Among faculty, there are significant differences by discipline and faculty rank in the acceptance and use of the Web. Faculty are frequently skeptical of the reliability of the information and about their students' ability to evaluate it. ${ }^{10}$ Although students consider themselves to be able users of Internet information technologies, there is a gap between what faculty expect and what students deliver. By assuming that students come to their classes proficient in using electronic and Internet resources, or that other areas on campus such as the libraries are filling this need, faculty may not give adequate instruction or guidelines to students for satisfactory completion of assignments. Susan Davis Herring found that "many faculty either restrict their students' use of the web, direct students to specific sites, or require students to obtain permission to use specific sites."11 She suggested that because "many faculty have doubts about students' ability to use the web and the information they find there effectively, this is an appropriate point for the introduction of information literacy training by library faculty."

\section{Usability of the Library Web Site for Col- lege and University Students}

Many studies have reported the difficulties users experience in navigating academic library Web sites. In a focus group study at Texas A\&M, researchers found that "there was an obvious need for clearer, simpler terminology to facilitate navigation and decision making." 12 Mark Spivey also has noted the need for clear terminology, stating "since successful navigation of a large library web site depends on the clarity of the home page, its vocabulary deserves scrutiny by managers of these internet sites."13

Use of library jargon is a significant obstacle to successful use of a Web site. Louise McGillis and Elaine G. Toms have reported that in a usability study of an academic library Web site, students "had difficulties interpreting menu labels, understanding the content of categories, and knowing where to start.... Participants did not know what heading to look under, ... and had difficulties with 'Databases,' 'Resources...' "14 They found that although 73 percent of the participants completed the task to find an Internet resource, this task took, on average, five times longer than the other five tasks because of difficulties in differentiating among terms used to describe Internet links. McGillis and Toms further observed that "web sites have not been structured to respond to information tasks. When people approach a website with a specific problem, they often cannot fit the problem into one of the options ... and cannot extrapolate from the list which tool/service is best suited to help them." Students in their study also displayed hesitation, 
demonstrating what the investigators described as "click cost," where "users are very reluctant to click unless they are fairly certain they will discover what they are looking for."

Similarly, Susan Augustine and Courtney Greene found jargon to be a problem when they observed that participants in their study "consistently demonstrated difficulty in evaluating the functions and uses of a wide variety of electronic resources. In many cases, the lack of understanding of jargon impacted their ability more than the organization of the site did."15 Unclear labels such as "resources," "databases," and "research" obfuscate the content of the library Web site. In addition, they found that "every participant but one [who indicated limited Internet experience] used the 'web site search' ... rather than attempting to retrieve information through the site's subject organization.... Participants consistently desired an easy and familiar search process-regardless of the accuracy of the search's results." This reinforced the findings of Tiffini Anne Travis and Elaina Norlin, who reported that "students reverted to what appeared to be a familiar way of finding things online-using search engines rather than navigating through a hierarchical order of web pages."16 There are conflicting reports of the value of annotated entries as a strategy for guiding users through the myriad choices. Laura Cohen and Julie M. Still noted that "annotations were in short supply on the pages [they] investigated. Users ... are being left to discover the differences for themselves without the benefit of a librarian's assessment."17 Conversely, Landon Fraser and Craig Locatis found evidence indicating that "annotations [have] virtually no effect on search performance" and that "the wording in links has primacy over the wording in annotations in influencing user search behavior." 18 The dilemma faced by Web designers in selecting appropriate terminology and the difficulty users have in navigating large Web sites is a reminder of why libraries use rigorous naming conventions for content. ${ }^{19}$

\section{Instruction for Internet Literacy}

There are divergent beliefs about the level of student experience and sophistication in Internet use; most reports of high student competency with the Web are student self-reported. Angela Weiler noted that the results of a questionnaire administered to freshman students at SUNY Morrisville showed even lower experience levels than anticipated. ${ }^{20}$ Susan M. Colaric summarized research findings that "users looking for information on the world wide web have a difficult time developing search queries and using a search engine." ${ }^{21}$ Her study found that before instruction, undergraduate students demonstrated significant misunderstandings concerning search engines, specifically in the variations in scope and coverage, and the differences in search techniques. She sought the most effective of three methods for Internet instruction but did not find significant differences among the approaches; across all of the materials and instructional approaches, "participants increased in the number of appropriate terms included in the query, and were more likely to include Boolean operators."

Although more research needs to be done, it seems likely that many forms of instruction, including embedded instruction on search engine interface pages, can improve user performance. "Unlike the limited, carefully chosen, structured collections of libraries, the World Wide Web provides widespread accessibility to vast quantities of information; information whose content is uncontrolled, unfiltered, unorganised, and unclassified." 22 Yet, stu- 
dents will search the Internet with us or without us; it is imperative that librarians take leadership in making the Internet search experience a profitable one.

\section{Web Page Design Supporting Paths to the Internet}

Several recent studies have analyzed the paths and content of academic library Web sites. In a review of 113 mediumsized university libraries, Bradley P. Tolppanen, Joan Miller, and Martha $\mathrm{H}$. Wooden found that 70.4 percent of the sites linked to Web search engines. ${ }^{23}$ In a 1999 study, Cohen and Still compared two-year college and research university Web sites for content, functionality, and structure." They found that links to search engines were provided by 76 percent of research libraries and 64 percent of two-year colleges and that links to net directories were provided by 44 percent of research libraries and 46 percent of twoyear college libraries. Links to net subject resources were provided by 84 percent of research libraries and 60 percent of twoyear college libraries, and links to Internet tutorials were provided by 20 percent of research libraries and 52 percent of twoyear college libraries.

\section{The Current Study}

\section{Methodology}

This study analyzed the home pages of 114 academic libraries that are ARL members. It was conducted during August 2002 and repeated in June 2003. Changes in site organization and content over that period are reported. Data were entered on Excel spreadsheets to describe specific characteristics of paths and content. For this study, tutorials were defined as those that require interactivity by the user or were labeled as tutorials on the referring link. Guides were defined as static pages of explanation, charts, annotations, and examples. The phrase "Internet-searching page" was used to describe pages that included links to Internet search engines, guides, tutorials, and related content. The study examined sites for the following:

- Inclusion or omission of Internet search engines, guides, and tutorials;

- Terminology used to describe paths to search engines, guides, and tutorials:

- sites that used the direct terms "Web" or "Internet";

- sites that used library jargon;

- sites that used vague, noninformative terms;

- sites that required use of a "site search."

For the purposes of this study, to indicate the primary navigational path and nature of content and to eliminate redundancy, only the primary path was recorded. Sites that provided a direct link on the top page to Internet search engines and tools were consistently found also to offer multiple alternative paths.

- Structure and organization of search engine pages, specifically noting:

- annotated entries versus those that were "links only";

- entries that were divided into categories or simply arranged alphabetically;

- mention of the "invisible Web" or "hidden Web."

- Types and placement of Internet guides and tutorials. Each guide and tutorial was described as:

- being integrated on the Internetsearching page or isolated in another section;

- having specific content regarding the citation and evaluation of sources;

- being internally or externally prepared.

- Subject-specific pages, defined as sites where the only links to external Internet sites and search engines appeared on subject-specific guides prepared by librarians. Libraries that provided direct 
links to Internet-searching pages in addition to subject-specific pages were not included in this group.

\section{Results}

\section{Changes over Time}

Sites in this study were first examined in August 2002 and reviewed in June 2003. During that time, eighteen libraries that initially had links to Internet-searching pages at the top level had either eliminated the Internet-searching pages entirely or kept the content but moved the pages several levels deeper. Thus, pages that were once easily found became buried, locatable only by use of a site search.

\section{Inclusion or Omission of Internet Search Engines, Guides, and Tutorials}

Seventy-seven $(67 \%)$ of the 114 sites in this study had dedicated Internet-searching pages that presented search engines, guides, and tutorials. Eight libraries (8\%) presented Internet tutorials and guides without search engines. Twenty libraries (17\%) presented external Internet subject sites only on subject pages prepared by libraries. Nine libraries ( $8 \%$ ) made no mention of Internet searching or external Internet resources whatsoever.

\section{Terminology Used on Links That Led to Search Engines, Guides, and Tutorials}

Not surprisingly, the terminology used to describe Internet links was the single most important element in determining the ease or difficulty of linking to Internetsearching pages. The surprising finding was the high number of libraries that did not successfully indicate where such pages could be found. Specifically,

- Use of direct terms "Web" or "Internet": Only thirty-two (28\%) of the 114 library sites studied used sufficiently descriptive terms, specifically, "Web" or "Internet," to ensure that users would link to Internet search engine pages on

\begin{tabular}{|l|c|}
\hline \multicolumn{2}{|c|}{ TABLE 1 } \\
Descriptive Terms Used to \\
Describe Paths to Search Engines, \\
Guides, and Tutorials
\end{tabular}

the first click. The most common phrases were "search the Internet," "Internet search engines," "Web search," "Internet searching," and "search the Web." Table 1 shows the distribution of these terms, as well as additional ones used less frequently.

- Use oflibrary jargon: Thirty-six libraries (32\%) used library jargon that required a user to guess, and guess again, a successful path to Internet-searching pages. These terms included "electronic resources," "research resources," "reference tools" or "reference resources," "resources," and "collections." "Reference" resources headings typically link to an amalgam of dictionaries, directories, encyclopedias, almanacs, weather, calendars, and more, inconsistent with content found on Internet-searching pages. Links to any combination of "collections" or "resources" often include some combination of searching for electronic journals, online catalogs, peripheral research guides, and special 


\begin{tabular}{|c|c|}
\hline \multicolumn{2}{|c|}{$\begin{array}{c}\text { TABLE } 2 \\
\text { Library Jargon Terms Used } \\
\text { to Describe Paths to Search } \\
\text { Engines, Guides, and Tutorials }\end{array}$} \\
\hline Term & Frequency \\
\hline Electronic resources & 10 \\
\hline Research resources & 10 \\
\hline Reference tools & 9 \\
\hline Resources & 6 \\
\hline Collections & 1 \\
\hline
\end{tabular}

collections. The term "digital collections" is easily confused with "electronic resources," which can then be mistaken for a link to anything related to Internet searching. Table 2 shows the distribution of these terms.

- Use of vague, noninformative terms: Twenty-eight libraries (25\%) used vague terms, such as "help," "find," "quick search," or "facts and guides," which linked to anything and everything; they offer no context for users to expect Internet-searching information to be found. Placement of Internet-searching content under any of these headings is completely nonintuitive and subjective, guaranteed to lead to user frustration. Table 3 shows a complete listing of these terms.

- "Site search" as the only means of retrieval: Five sites had satisfactory Internet-searching pages but offered no links under any label at all; instead, these were retrieved only through a site search. This may have been a consequence of having recently revised home pages, retaining content while inadvertently omitting links. Although the lack of Internetsearching links amidst links for other content was misleading, the preference among undergraduate students to search directly in a site search box rather that to browse home page menus has been documented.

\section{Structure and Organization of Search}

\section{Engine Pages}

This section describes characteristics of the seventy-seven libraries that had dedicated Internet-searching pages.

- Annotated versus nonannotated links: Only nineteen of the seventy-seven libraries offered significant annotated explanations of the scope, content, advantages, and search strategy tips for each link. Annotations can help users make intelligent choices among search engines. A passage as simple as "Meta Search Engines: Search many search sites simultaneously" helps make important distinctions. Without explanations, users are more likely to conclude that search engines are of equal value for any particular information need.

- Categorization of entries: Twentythree sites arranged their Internet-search-

\begin{tabular}{|l|c|}
\hline \multicolumn{2}{|c|}{$\begin{array}{c}\text { TABLE 3 } \\
\text { Unclear Terms Attempting to } \\
\text { Describe Paths to Search Engines, } \\
\text { Guides, and Tutorials }\end{array}$} \\
\hline \hline Term & Frequency \\
\hline Search & 7 \\
\hline Quick links & 3 \\
\hline Instruction & 2 \\
\hline Starting research & 2 \\
\hline Books, articles, and more & 1 \\
\hline Facts and guides & 1 \\
\hline Find & 1 \\
\hline Find sites & 1 \\
\hline Help & 1 \\
\hline How do I? & 1 \\
\hline How-to guides & 1 \\
\hline "I need a" drop menu & 1 \\
\hline Library services & 1 \\
\hline Quick search & 1 \\
\hline Services & 1 \\
\hline $\begin{array}{l}\text { What are you looking for? } \\
\text { [drop menu] }\end{array}$ & 1 \\
\hline
\end{tabular}


ing entries in alphabetical order, thereby failing to indicate to users, through entry organization, the comparative uses and strengths of the search engines. Fiftythree sites categorized entries into types of search engines such as meta-search engines, directories, and so on; and this categorization was beneficial to help make distinctions and choices. Nineteen sites provided even more advanced capabilities for searching specialized information, such as categories dedicated to special engines for "business," "people," "academic information," "news and current events," "list" (listserv) sites, and audio, video, and graphics, and more.

- The "invisible Web"|"hidden Web": Although sites such as Librarian's Index to the Internet and the Argus Clearinghouse frequently appeared on search engine pages, their unique ability to focus on specialized information was usually not described. Only twelve sites even mentioned the "invisible Web" or "hidden Web" as a unique category, and only seven of those twelve defined it.

\section{Guides and Tutorials}

Libraries provided multiple combinations of user guides and tutorials. Of the 114 sites, fifty $(44 \%)$ provided links to informational user guides and comparisons of search engines, and thirty-seven $(32 \%)$ linked to tutorials. Sixteen libraries $(14 \%)$ linked to both guides and tutorials. Of these guides, those specifically relating to citing and evaluating Internet materials were common: thirty-six for citing, and forty for evaluating Web sources. Only eighteen sites (16\%) provided search engine links only, with no supporting documentation, user guides, or instruction. Although guides were always presented on the same page as the links to search engines, tutorials were more often isolated, found only through a link related to library instruction or information literacy or through a site search. Guides were more often externally prepared, whereas tutorials were more often prepared internally as part of a larger research tutorial. Frequently linked guides were Search Engine Watch (http:// searchenginewatch.com), Search Engine Showdown (http://www.searchengineshowdown.com), and the University of California-Berkeley's Finding Information on the Internet (http://www.lib.berkeley. edu/TeachingLib/Guides/Internet/FindInfo.html\#Outline).

\section{Subject-specific Pages}

For twenty of the 114 libraries (17\%), external Internet sites were mentioned only on subject-specific guides prepared by librarians; only two of these twenty mentioned search engines or Internet-searching guides. There is great variation in the number of external subject links included on subject-specific pages, ranging from two or three to more than fifty or seventy-five. These pages usually represent the most important sites in the discipline and may reflect the teaching priorities of faculty but do not offer a path to extend searching beyond the libraries.

\section{Discussion}

Libraries are increasingly using the Web to direct users to resources beyond their own licensed collections, but there is a striking and disturbing inconsistency among libraries in the presentation of these Internet-searching resources. This research found that 67 percent of the sites studied have dedicated Internet-searching pages that include search engines, guides, and tutorials. However, only 28 percent used sufficiently descriptive terms to help ensure that users would link to Internet search engine pages on the first click; most used jargon or vague terms. Eight percent did not mention the Internet at all. The evidence is strong that students rely 
heavily on the Internet for academic and personal information needs. Libraries that do not offer high-quality Internet search engine links, user guides, and instruction lose a great opportunity to attract students and to position themselves as the primary gateway for information. Academic libraries can significantly enhance access to Internet-searching resources by focusing attention on the following:

- Vocabulary: Vague or jargon terms such as "resources," "databases," "research," "help," and "find" obfuscate the content of the library Web site; they have multiple possible meanings and are not sufficiently descriptive. The most common phrases judged to be successful were "search the Internet," "Internet search engines," "Web search," "Internet searching," and "search the Web."

- Web page design: Library sites with Internet-searching pages that are not prominently linked from their top page should reconsider the design of their page. It is perplexing to understand why some library sites that at one time gave prime attention to Internet-searching content chose to diminish the accessibility to that content. It is difficult for even an experienced library user to guess what a particular library might choose to include within various descriptive sections of its Web pages. In the course of this study, the author's review of many library pages was a true exercise in frustration; the average user would most certainly not have pursued browsing to the degree that was done for this review. Worse, when it was necessary to review a site multiple times, the page design was so poor that the experience of conducting the earlier searches was no help in conducting the subsequent review. Sites should be designed to respond to information tasks. Sites that rely exclusively on site search capabilities do not support multiple learning styles. Sites that use graphics only, particularly on the page perimeter, were judged to be much less effective in capturing attention and were easily overlooked. Sites that had links only on the left bar, whether textual or graphic, were judged to be less effective than those placed in the central portion of the page. Sites that organize search engines by functional categories and specialization can be very useful in forming cognitive frameworks for search engines. Arrangement of search engine content by category is a natural organizer for students to see critical distinctions.

- Content: Given that Internet resources are a primary research choice for university students, librarians should direct students to excellent Internet resources and guides in the same way they do for traditional library resources. Librarianprepared subject pages, though valuable, are no substitute for the tools that support independent and intelligent consumers of information beyond the libraries' collections. Emphasis on the invisible Web is an important approach to access selective and high-quality resources, helping users distinguish between types of information on the Internet and teaching valuable evaluation criteria; failure to highlight the invisible Web is a serious omission. Annotations represent the value-added content that librarians can and should provide to allow users to make intelligent choices and to influence students' Internet information choices. Without annotations, users are more likely to conclude that search engines are of equal value for any particular information need. Sites with very brief, but cogent, annotations about sites or strategies are the most successful; longer annotations clutter the page and are frequently ignored. Internet guides are extremely important to be presented along with search engine links; sites that lack supporting material are incomplete. More sites should consider integrating tutorials with guides; instructional efforts 
may be strengthened by making stronger links between tutorials and related content pages. Because significant resources are invested in tutorial development, it would seem wise to maximize their use.

\section{Conclusion}

Academic librarians consider that part of their mission is to serve as the gateway to information for their institution. They claim a significant responsibility for teaching information literacy. The propensity for students, especially undergraduates, to use Internet search engines is well documented. Given this reality, it is highly desirable for them to maximize their ability to incorporate the Internet on the library Web site to enable students to make the best search engine choices and to apply the best Internet search strategies. A well-designed presentation of Internet-searching content is also an opportunity to help clear blurred user impressions of library resources versus Internet resources. Libraries should demonstrate that they are positioning themselves to meet the challenges of the new information environment. Students will search the Internet or without us; it is to their benefit and ours that we provide paths to help integrate the Internet with licensed library resources.

\section{Notes}

1. Louise McGillis and Elaine G. Toms, “Usability of the Academic Library Web Site: Implications for Design," College \& Research Libraries 62 (July 2001): 355-67.

2. Mignon Adams and Richard M. Dougherty, "How Useful Is Your Homepage?" College and Research Library News 63 (Sept. 2002): 590-92.

3. Association of College and Research Libraries, "Information Literacy Competency Standards for Higher Education." Available online from /http://www.ala.org/acrl/ilcomstan.html. [Accessed 8 August 2003].

4. Ross Todd, "Information Literacy in Electronic Environments: Fantasies, Facts, and Futures" (paper presented at the 2000 IATUL Conference, Brisbane, Queensland, Australia, July 2000. Available online from http://educate.lib.chalmers.se/iatul/proceedcontents/qutpap/todd_full. html. [Accessed 8 August 2003].

5. Pew Internet Project, Pew Internet and American Life, "The Internet Goes to College: How Students Are Living in the Future with Today's Technology," Sept. 15, 2002. Available online from http://www.pewinternet.org/reports/reports.asp?Report=71\&Section=ReportLevel1\&Field=Leve 11ID\&ID=312. [Accessed 8 August 2003].

6. OCLC Online Computer Library Center, Inc., "OCLC White Paper on the Information Habits of College Students: How Academic Librarians Can Influence Students' Web-based Information Choices," June 2002. Available online from http://www5.oclc.org/downloads/community/informationhabits.pdf. [Accessed 8 August 2003].

7. Denise Troll, "How and Why Are Libraries Changing?" (draft), Digital Library Federation, Jan. 7, 2001. Available online from http://www.diglib.org/use/whitepaper.htm. [Accessed 8 August 2003].

8. Deborah J. Grimes and Carol H. Boening, "Worries with the Web: A Look at Student Use of Web Resources," College \& Research Libraries 62 (Jan. 2001): 11-23.

9. Steve Lawrence and Lee Giles, "Accessibility of Information on the Web," Nature 400 (July 8, 1999): 107-9.

10. Bruce Heterick, "E-content: Faculty Attitudes toward Electronic Resources," Educause Review (July/Aug. 2002): 10-11. Available online from http://www.educause.edu/ir/library/pdf/ erm0248.pdf. [Accessed 8 August 2003].

11. Susan Davis Herring, "Faculty Acceptance of the World Wide Web for Student Research," College \& Research Libraries 62 (May 2001): 251-58.

12. Gwyneth H. Crowley, Rob Leffel, Diana Ramirez, Judith L Hart, and Tommy S Armstrong, "User Perceptions of the Library's Web Pages: A Focus Group Study at Texas A\&M University," Journal of Academic Librarianship 28 (July 2002): 205-10.

13. Mark Spivey, "The Vocabulary of Library Home Pages: An Influence on Diverse and Remote End-Users," Information Technology and Libraries 19 (Sept. 2000): 151-56.

14. McGills and Toms, "Usability of the Academic Library Web Site."

15. Susan Augustine and Courtney Greene, “Discovering How Students Search a Library Web 
Site," College \& Research Libraries (July 2002): 354-65.

16. Tiffini Anne Travis and Elaina Norlin, "Testing the Competition: Usability of Commercial Information Sites Compared to Academic Library Web Sites," College \& Research Libraries 63 (Sept. 2002): 433-48.

17. Laura Cohen and Julie M. Still, "A Comparison of Research Library and Two-year College Library Web Sites: Content, Functionality, and Form," College and Research Libraries 60 (May 1999):275-89.

18. Landon Fraser and Craig Locatis, "Effects of Link Annotations on Search Performance in Layered and Unlayered Hierarchically Organized Information Spaces," Journal of the American Society for Information Science and Technology 52 (Dec. 2001): 1255-61.

19. Steven W. Sowards, "A Typology for Ready Reference Web Sites in Libraries," First Monday 3 (May 4, 1998). Available online from http://www.firstmonday.dk/issues/issue3_5/sowards/index. html. [Accessed 8 August 2003].

20. Angela Weiler, "Two-year College Freshmen and the Internet: Do They Really 'Know All That Stuff'?" portal: Libraries and the Academy 1 (2001): 161-67. Available online from http://muse. jhu.edu/journals/portal_libraries_and_the_academy/v001/1.2weiler.pdf. [Accessed 8 August 2003].

21. Susan M. Colaric, "Instruction for Web Searching: An Empirical Study," College and Research Libraries 64 (Mar. 2003): 111-22.

22. Todd, "Information Literacy in Electronic Environments."

23. Bradley P. Tolppannen, Joan Miller, and Martha H. Wooden, "An Examination of Library World Wide Web Sites at Medium-sized Universities," Internet Reference Services Quarterly 5 (2000): 5-17.

24. Cohen and Still, "A Comparison of Research Library and Two-year College Library Web Sites." 